\title{
ONLINE DISPUTE RESOLUTION FOR Small Civil Claims in Victoria: A NeW Paradigm In CiviL Justice
}

\section{VIVI TAN*}

This article seeks to explore some of the implications of integrating information and communications technology into judicial processes to resolve small civil claims. It argues that, as ODR moves from individual private-sector initiatives to widespread public sector institutionalisation, governance and value questions will need to be seriously considered. This is because questions regarding the appropriateness of the use of certain ODR systems in the resolution of small claims and consumer disputes persist, especially in relation to the use of systems which are fully autonomous. For example, how are fundamental due process requirements to be balanced against the economic constraints of resolving low value disputes? What are the limits to the evolution of civil justice to make it more accessible? It is argued that, while ODR holds vast potential for increasing access to justice, attention needs to be given to the dispute system design to ensure that it achieves that goal and does not result in the erosion of fundamental values of civil justice, including accessibility, transparency, legal validity and accountability.

\section{INTRODUCTION}

In September 2018, as part of a new digital strategy to enhance online services and improve efficiency, the Victorian Civil and Administrative Tribunal ('VCAT') implemented an online dispute resolution ('ODR') pilot. ${ }^{1}$ Parties were able to have their matters heard and resolved by a VCAT member in real

\footnotetext{
* Vivi Tan is an Honorary Fellow at the University of Melbourne Law School where she is completing her PhD. She would like to thank her supervisors, Professor Jeannie Paterson and Professor Julian Webb, for their advice and guidance.

1 'Sharing VCAT's Online Dispute Resolution Experience', VCAT (21 November 2018) ('VCAT's Online Dispute Resolution Experience') <https://www.vcat.vic.gov.au/news/sharing -vcats-online-dispute-resolution-experience>.
} 
time using video and file sharing technology on their own devices as an alternative to attending a hearing in person.

This pilot was in line with one of the recommendations from the 2016 Victorian Government Access to Justice Review. ${ }^{2}$ The Review recommended that the Victorian Government provide pilot funding and, subject to evaluation, ongoing funding for the development and the implementation of a new online system for the resolution of small civil claims. ${ }^{3}$

This article will seek to explore some of the implications of integrating information and communications technology into judicial processes to resolve small civil claims. Many jurisdictions, including the province of British Columbia in Canada, ${ }^{4}$ China, ${ }^{5}$ the United States, ${ }^{6}$ Mexico ${ }^{7}$ and the United Kingdom, ${ }^{8}$ are seizing the opportunities offered by new technologies to modernise dispute resolution systems. They have adopted systems that attempt to provide support, intake, advisory and determinative processes. These are designed to increase access to justice for consumers who traditionally would not bring their claims before a tribunal or a court due to constraints such as costs, location, time, and information asymmetry. Consumers are provided with more avenues to resolve disputes in a speedy and flexible manner, without reliance on traditional court processes which can be slow, inflexible and costly.

However, despite these benefits, questions regarding the appropriateness of the use of certain ODR systems in the resolution of small claims and consumer disputes persist, especially in relation to the use of systems which are fully autonomous. This article contends that, while ODR holds vast potential for increasing access to justice, care needs to be given to the dispute system design to ensure that it achieves that goal. Furthermore, as ODR moves from individual private-sector initiatives to widespread public sector institutionalisation, governance and value questions will undoubtedly come to the fore. For

${ }^{2}$ Victoria State Government, Access to Justice Review: Volume 1 Report and Recommendations, (Report, August 2016) Recommendation 5.2, 281 ('Access to Justice Review') <https://s3.apsoutheast-2.amazonaws.com/hdp.au.prod.app.vic-engage.files/3314/8601/7221/Access_to_ Justice_Review_-_Report_and_recommendations_Volume_1.PDF>.

${ }^{3}$ Ibid.

${ }^{4}$ Civil Resolution Tribunal [British Columbia] (Web Page) <https://civilresolutionbc.ca/>.

5 'The Litigation Platform of Hangshou Internet Court', Hangzhou Internet Court (Web Page) <https://www.netcourt.gov.cn/portal/main/en/index.htm>.

6 Deno Himonas, 'Utah's Online Dispute Resolution Program' (2018) 122(3) Dickinson Law Review 875.

${ }^{7}$ Concilianet (Web Page) <http://concilianet.profeco.gob.mx/Concilianet/inicio.jsp>.

8 'Make a Court Claim for Money', GOV.UK (Web Page) <https://www.gov.uk/make-courtclaim-for-money>. 
example, how are fundamental due process requirements to be balanced against the economic constraints of resolving low value disputes? What are the limits to the evolving accessibility of civil justice? And how will an ODR system impact the existing alternative dispute resolution ('ADR') processes in tribunals such as VCAT?

Further and more broadly, to what extent should technology be relied upon to provide dispute resolution services for consumers, considering the risk of sacrificing certain values — accessibility, legal validity, transparency and accountability - that are vital to the due administration of civil justice. This article will both inform and contribute to the debate on these questions and on the implications for consumer dispute regulation and practice. It will do this by defining ODR systems in Part II, and distinguishing examples of non-ODR systems. ODR systems will be classified by reference both to their platform and their level of automation or intelligent capability. In connection with its main argument, this article will contend that a discussion of the potential for ODR systems to increase efficiency in the resolution of small civil claims must begin with an adequate analysis of the different classifications of such systems.

Part III analyses how other jurisdictions have adopted different types of ODR systems to illustrate the various system designs which can potentially be adopted by a tribunal such as VCAT. Part IV will in turn focus on the judicial resolution of small claims in VCAT and the potential implications of the integration of an ODR system into VCAT's dispute resolution systems. Part V will contain an analysis of some of the potential benefits of ODR and a discussion of juridical values such as legal validity, transparency and accountability in ODR. Ultimately, it is submitted that a discourse on ODR must necessarily include an integrated assessment of efficiency-oriented factors as well as of the fundamental values of civil justice.

\section{DEFINING ODR}

\section{A Non-ODR Systems}

Various names, such as Electronic Dispute Resolution ('EDR'), Internet Dispute Resolution ('IDR') and Online Alternative Dispute Resolution ('OADR') have been used interchangeably to describe ODR. ${ }^{9}$ It is also common

\footnotetext{
${ }^{9}$ Haitham A Haloush, 'The Liberty of Participation in Online Alternative Dispute Resolution Schemes' (2008) 36(1) International Journal of Legal Information 102, 103; Beatrice Baumann, 'Electronic Dispute Resolution (EDR) and the Development of Internet Activities' (2002) 52 Syracuse Law Review 1227, 1228; Richard Michael Victorio, 'Internet Dispute
} 
for the term 'ODR' to be used to describe online communication facilities which allow parties or customers to lodge their complaints and to be connected with the other party to the dispute but without a dispute resolution mechanism operating alongside this facility. ${ }^{10}$

ODR has also been defined exclusively as the use of alternative dispute resolution methods, such as negotiation, mediation and arbitration which are assisted by information communication tools. ${ }^{11}$ To further complicate the matter, some online ADR concepts such as online mediation have been used to describe a large number of systems from automated blind-bidding processes and e-mediators to online mediation platforms with human facilitators and case management functionalities. Terms have often been used interchangeably. ${ }^{12}$ The resulting lack of clear definition and specificity unfortunately impedes clear analysis of the ODR concept and the potential of ODR to be a system that can allow parties to resolve their disputes by using a neutral facilitator or a neutral decision maker, or even through the use of algorithms or artificial intelligence.

This Part argues that a true ODR system should be defined as a system that allows parties to resolve their disputes from beginning to end, that is, from the making of the claim to the resolution of the dispute, in an online forum. There are three main groups of systems that should be distinguished from a true ODR system at the outset. These include: 1) systems which enable electronic filing ('eFiling') or online management of cases and hearings and electronic discovery, 2) online information platforms, and 3) online documents storage and retrieval platforms.

Some examples of an eFiling system include the VCAT Residential Tenancies Hub that allows tenants and landlords to create notices, apply to VCAT, pay

Resolution (IDR): Bringing ADR into the 21st Century' (2001) 1(2) Pepperdine Dispute Resolution Law Journal 279, 280; Michael Legg, 'The Future of Dispute Resolution: Online ADR and Online Courts' (2016) 27 Australasian Dispute Resolution Journal 227, 227; Julia Hörnle, 'Online Dispute Resolution in the EU and Beyond: Keeping Costs Low or Standards High?' in Christopher Hodges and Astrid Stadler (eds), Resolving Mass Disputes ADR and Settlement of Mass Claims (Edward Elgar, 2013) 293, 294.

10 David Carneiro et al, 'Online Dispute Resolution: An Artificial Intelligence Perspective' (2014) 41(2) Artificial Intelligence Review 211, 215 ('Online Dispute Resolution').

${ }^{11}$ See for example, Aashit Shah, 'Using ADR to Resolve Online Disputes' (2004) 10(3) Richmond Journal of Law and Technology 1; Gabrielle Kaufmann-Kohler and Thomas Schultz, Online Dispute Resolution: Challenges for Contemporary Justice (Kluwer, 2004) 5; David Spencer and Samantha Hardy, Dispute Resolution in Australia: Cases, Commentary and Materials (Thomson Reuters, 2014) 648.

${ }^{12}$ Kaufmann-Kohler and Schultz (n 11) 6. 
fees and search for previous notices and applications online. ${ }^{13}$ Similarly, eFiling or eLodgment platforms such as the Redcrest eFiling platform utilised by the Supreme Court of Victoria ${ }^{14}$ or the eLodgment and eCourtroom facilities available in the Federal Court ${ }^{15}$ are facilitative online systems which are not ODR systems. The Federal Court eCourtroom was developed as early as 2001. It is an online courtroom that can be used by judges and registrars to assist with the case management and hearing of certain matters before the Federal Court or the Federal Circuit Court of Australia. Such matters include the giving of directions, ex parte applications for substituted service in bankruptcy proceedings, applications for examination summonses and other orders in general federal law matters. The eCourtroom is integrated with eLodgment, thereby facilitating the electronic filing of documents. It is an efficient online facilitative system which not only allows for an exchange of documents, but also for the making of submissions in a protected and confidential environment.

The second group of non-ODR systems comprises online information platforms which focus on dispute resolution but do not provide processes or facilities which allow parties to resolve their disputes thereby. An example is the online information package provided by the Dispute Settlement Centre of Victoria directed at disputants in neighbourhood conflicts. Another example is the Family Relationship Services Online. ${ }^{16}$ This service provides all families, including partners who are separated, with information about family relationship issues. The information ranges from how to build a better relationship to dispute resolution, including, for example, information about Family Dispute Resolution and links to accredited Family Dispute Resolution Providers.

Finally, an example of an online storage platform is the Commonwealth Courts Portal. This portal is a joint initiative of the Family Court of Australia, the Federal Court of Australia and the Federal Circuit Court of Australia. ${ }^{17}$ It provides web-based services for authorised users, such as a lawyers, judges,

\footnotetext{
13 'How to Register for the Residential Tenancies Hub', VCAT (Web Page) $<$ https://www.vcat.vic.gov.au/get-started/renting-a-home/how-to-register-for-the-residentialtenancies-hub>.

14 Supreme Court of Victoria - Electronic Filing (Web Page) <https://www.redcrest. com.au/eservices/home.page.2>.

15 'eLodgment', Federal Court of Australia (Web Page) <http://www.fedcourt.gov.au/onlineservices/elodgment>; 'eCourtroom', Federal Court of Australia (Web Page) <http://www.fedcourt.gov.au/online-services/ecourtroom>.

${ }^{16}$ Family Relationships Online (Web Page) <https://www.familyrelationships.gov.au/> .

17 Commonwealth Courts Portal (Web Page) <https://www.comcourts.gov.au/>; 'Federal Law Search', Federal Court of Australia (Web Page) <http://www.fedcourt.gov.au/onlineservices/federal-law-search>.
} 
litigants and journalists, so that they can immediately access information on cases before the courts, including a list of the court files or files of interest to the user. Like eCourtroom and eLodgment, this type of data management, storage and retrieval system is not an ODR system. Discussion will now turn to the different types of true ODR system based on their level of automation.

\section{B Level of Automation Spectrum}

\section{$1 \quad$ Automation of Offline Interactions}

ODR systems are various types of dispute resolution procedures facilitated by different technological tools. They can be differentiated through their level of automation and function. This classification based on the level of automation focuses on the functionality of the ODR system. At one end of the spectrum, ODR can include technology-based substitution or automation of offline interactions and activities. For example, ADR processes such as mediation and arbitration might be conducted online by a human mediator or arbitrator and might be synchronous, that is, attended by the disputing parties in real time using video-conferencing tools. Some commentators have referred to this type of system as the 'first generation' ODR system. ${ }^{18}$

Central to such a system is the involvement of human actions in the planning, managing and decision-making processes. The use of information and communications technology is facilitative or supportive in this regard. Communication between the parties, as well as between the parties and the ODR provider, can occur both synchronously and asynchronously, using emails, instant messaging, video and phone calls. Software such as Skype or the web-based video-conferencing platform Zoom can be used to facilitate the online hearing. Moreover, the dispute and all associated files can be managed and stored online in a secured database.

In some cases, the first generation ODR systems can be used in conjunction with automated negotiation software to enable a tiered dispute resolution process. Some of these examples will be discussed in the following segment of the article.

\section{Online Conciliation}

The Australian Financial Complaints Authority ('AFCA') assists consumers and small businesses to reach agreements with financial firms in settlement of

\footnotetext{
${ }^{18}$ Carneiro et al (n 10) 214-5.
} 
complaints about financial services, including credit, finance, insurance, banking and investment, as well as superannuation. These complaints were previously handled by three different bodies - the Financial Ombudsman Service, the Credit and Investments Ombudsman and the Superannuation Complaints Tribunal. AFCA now provides both formal and informal methods to resolve consumer complaints, including a telephone conciliation conference. $^{19}$

Overseas, the Concilianet platform in Mexico is both hosted and supported by the Office of the Federal Attorney for the Consumer ('PROFECO') and it offers an entirely free online conciliation system for dispute resolution. ${ }^{20}$ Suppliers of goods and services that have entered into collaboration agreements with PROFECO can utilise this online conciliation hearing platform should a customer file a complaint against them. These suppliers range from airline companies, entertainment suppliers, e-commerce sites, restaurants and telecommunication providers, to real estate companies. ${ }^{21}$ Suppliers which are not registered can have claims filed against them, but the filing must be done in person at a local satellite office. ${ }^{22}$ The use of this platform is voluntary, and it does not prevent the consumer from bringing their claim to the court. ${ }^{23}$

\section{Online Negotiation and Mediation}

In addition to online conciliation, the rapid growth of online negotiation and mediation can be seen in both judicial and extra-judicial resolution of disputes. ${ }^{24}$ For instance, the British Columbia Civil Resolution Tribunal ('CRT') offers ODR for strata property disputes (with no maximum value) and small claims disputes to the value of CAD 5000. The dispute resolution process involves four steps: 1) use of an information platform, 2) party-to-party negotiation, 3 ) online conciliation facilitated by mediators and 4) in cases where parties do not reach a negotiated agreement, adjudication by the tribunal member. This illustrates the ability of an ODR system to integrate both traditional and ADR processes to encourage parties to resolve their disputes

\footnotetext{
${ }^{19}$ Australian Financial Complaints Authority (Web Page) <https://www.afca.org.au/what-toexpect/the-process-we-follow/>.

${ }^{20}$ Concilianet (n 7).

21 'Participating Providers', PROFECO (Web Page) <https://concilianet.profeco.gob.mx/ Concilianet/proveedores_que_concilian.jsp>.

22 'Frequently Asked Questions', PROFECO (Web Page) < https://concilianet.profeco. gob.mx/Concilianet/faq.jsp>.

${ }^{23}$ Ibid.

${ }^{24}$ Pablo Cortés, Online Dispute Resolution for Consumers in the European Union (Taylor \& Francis, 2011) 144-5 <http://www.oapen.org/search?identifier=391038>.
} 
early in the resolution process. It is highly likely that similar systems will be more commonplace in the near future due to the increasing annexation of ADR processes by court and tribunal systems.

One early dominant player on the extra-judicial online negotiation and mediation scene was SquareTrade. ${ }^{25}$ From 1996 to 2008, it assisted eBay users worldwide in resolving their small value disputes using online mediation. It attempted to leverage concepts used in offline ADR to create the largest ODR system at the time. Thus, the model deployed processes of assisted negotiation, conciliation and mediation, and users had the option of choosing mediators or a recommended resolution. These could be utilised both as facilitated services and through the use of automatic negotiation software that matched solutions to problems. In other words, SquareTrade used the combination of an online mediation and a negotiation software.

SquareTrade was self-contained as it dealt only with disputes arising online. Parties who failed to resolve their disputes through direct negotiation would be referred to SquareTrade. The system was used to settle disputes in a number of online market places, including eBay. Disputants repeatedly presented disputes involving the same issues, and thus it was possible to divide these disputes into different categories. The main categories of dispute involved delivery delays, bad or incorrect descriptions of goods and negative feedback. ${ }^{26}$ It is not surprising that dispute resolution on a platform such as eBay is a necessity. The platform advertises a large number of items for sale, it facilitates a large number of transactions, and eBay Inc itself assumes little responsibility for the transaction. The availability of a dispute resolution process and the use of credit card chargebacks has thus turned platforms such as eBay into online marketplaces where buyers and sellers can transact on almost anything without a high degree of risk.

The first element in the SquareTrade system was a triage mechanism. When a buyer or a seller filed a complaint, they would be asked to fill out a web-based standard claim form that identified the type of dispute. ${ }^{27}$ They would then be presented with a list of common solutions that they could agree to. The other party to the dispute would be contacted by e-mail and informed about the process. They were asked to confirm their agreement to participate. This first step can best be described as an assisted negotiation process that employs

\footnotetext{
${ }^{25}$ Thomas Schultz, 'Does Online Dispute Resolution Need Governmental Intervention: The Case for Architectures of Control and Trust' (2004) 6(1) North Carolina Journal of Law and Technology 71, 74.

${ }^{26}$ Cortés (n 24) 68.

${ }^{27}$ Ibid 67.
} 
negotiation support systems. The process was designed to interpret the parties' claims, match their potential interests in the outcome of the dispute and offer a solution. The negotiation technology helped convert the parties' claims into constructive and clear language. If both parties agreed on the same solutions, the dispute would be considered resolved. However, if they did not come to an agreement, the next stage of the resolution would be triggered. ${ }^{28}$

This next stage mimicked a negotiation environment and used software tools to promote constructive negotiation between the two parties. Using the web interface, parties were allowed to formulate and reformulate the problem and the desired solution. The aim of this procedure has been described as working 'toward the goal of Pareto efficiency in negotiation'. ${ }^{29}$ Parties were limited in the number of texts they could insert. This was to prevent parties from introducing other less relevant elements into the negotiation which might have the effect of escalating the dispute. Parties were also encouraged to propose an agreement and set deadlines. As a result, parties were encouraged to move from a problem or disputing mode to a solution stance. ${ }^{30}$ Disputes which were not settled during the first two stages proceeded to the next stage which involved assisted mediation by a mediator acting as expert evaluator or conciliator. ${ }^{31}$

SquareTrade utilised mediators from over 15 different countries ${ }^{32}$ In managing the process, they would carry out responsibilities similar to those of offline mediators, uncovering the parties' interests and directing them toward a mutually acceptable resolution. If the parties reached an agreement, the mediator would draft the memorandum of understanding for them to accept. ${ }^{33}$ The mediator would communicate in writing (through asynchronous e-mail and web communication) with each party separately in trying to lead them toward a resolution. No video communication technology was used, something which could have introduced another facet to online mediation.

\footnotetext{
${ }^{28}$ Ibid.

${ }^{29}$ Ernest M Thiessen and Joseph P McMahon, 'Beyond Win-Win in Cyberspace' (2000) 15(3) Ohio State Journal on Dispute Resolution 643, 666. A transaction is Pareto-efficient if it satisfies the preferences of at least one party and does not cause a violation of the preferences of anyone else. For example, in a negotiation between A and B, A has a preference for a claim which it values at $\$ 5$ and which $B$ values at $\$ 10$. The negotiation is Pareto efficient if $B$ in fact fully compensates A for the value of its claim (\$5) and is nevertheless content because it has parted with less than $\$ 10$, and if no one else is made worse off because of the negotiation.

30 Orna Rabinovich-Einy, 'Technology's Impact: The Quest for a New Paradigm for Accountability in Mediation' (2006) 11 Harvard Negotiation Law Review 253, 258.

${ }^{31}$ Cortés (n 24) 67.

32 Ibid 149.

${ }^{33}$ Ibid.
} 
Approximately $80 \%$ of disputes handled by SquareTrade were resolved in the first two stages, involving efficient automatic processes that enhanced online negotiation. ${ }^{34}$ Cortés contends that the simplicity and the convenience of the system led to its high level of success in resolving eBay disputes for over eight years. ${ }^{35}$ Further, he argues that factors such as the "nature of the dispute, the accuracy of information provided and the capability of the software or the neutral third party in assessing and evaluating the facts and evidence' could influence the success of the consensual and automated processes. ${ }^{36}$ And, perhaps more importantly, the parties who were involved in the dispute sellers who wanted to obtain positive feedback from their customers and buyers who wanted redress - often had incentives to participate. ${ }^{37}$ The feedback or reputation management system played an important role in the success of the ODR process. However, after eight years of success, eBay Inc made the decision to bring ODR in-house and continues to provide such services through its Resolution Centre. It has been said that the demise of SquareTrade was brought about by its inability, as a third-party service provider outside of the eBay network, to resolve many non-feedback related disputes. ${ }^{38}$ PayPal and other large online marketplaces such as Alibaba now also offer their own internal Resolution Centres, with Alibaba going as far as introducing a User Dispute Resolution Centre which enables Taobao (Alibaba's consumer-toconsumer online marketplace) users to play judge and jury in disputed ecommerce transactions. ${ }^{39}$

One of the benefits of submitting to a self-contained ODR platform is that the community or marketplace itself has in-built enforceability mechanisms that can respond to parties that fail to comply with the outcomes of a dispute resolution process. For example, eBay Inc can act against non-compliant parties through suspension of accounts or it can institute a delay in payment or even reverse charges and allow money to be refunded to the customer. Such a chargeback facility is an important tool in such a platform. This, combined with the internal trust mark system, allows for a wholly internal system of dispute resolution that binds parties who have indirectly submitted themselves to the

\footnotetext{
${ }^{34}$ Ethan Katsh and Janet Rifkin, Online Dispute Resolution: Resolving Conflicts in Cyberspace (John Wiley, 2001) 142.

${ }^{35}$ Cortés (n 24) 68.

${ }^{36}$ Ibid.

${ }^{37}$ Ibid.

${ }^{38}$ SquareTrade's original dispute resolution service as well as its merchant verification service have since been discontinued.

39 'Managing Customer Concerns', PayPal Australia (Web Page) < https://www.paypal. com/au/webapps/mpp/customer-concerns>; Alibaba Public Jury (Web Page) <http://pan. taobao.com/>.
} 
dispute resolution mechanisms when voluntarily entering into the agreement to use the marketplace and to become a member of the community. The coercive nature of the system is justified on the basis of the parties' voluntary agreement to join the marketplace.

Similarly, Amazon Pay offers a Buyer Dispute Program which will apply if a customer has used Amazon payment to purchase a physical item and the item does not arrive or is materially different from the description. In such a case the customer is eligible to receive up to USD 2,500 of the purchase price including shipping charges. ${ }^{40}$ Customers who use their credit cards through Amazon payments can also elect to dispute any charge with their issuing banks. In cases where buyers abuse the Buyer Dispute Program or chargeback rights, their access to their accounts can be restricted or terminated. Similarly, any merchant who fails to cooperate in good faith in trying to resolve its buyers' complaints may face the consequence of having its account privileges restricted or terminated. ${ }^{41}$

Ultimately, these providers act as neutral third parties which encourage business and consumers to first reach amicable agreements through automated negotiation and, in cases where such agreements are not formed, these providers can also adjudicate the disputes. However, despite the many benefits provided, these private platforms are unregulated and unmonitored for fundamental fairness and due process protections. This being the case, arguments can be made for the development of a regulatory framework to govern these platforms to ensure that fundamental values of civil justice, as well as other important values such as privacy protection, are upheld by any ODR platform regardless of its public/private categorisation. ${ }^{42}$

Another example of automated negotiation which can utilise both online mediation and automated software is blind bidding. ${ }^{43}$ It can be effectively used

\footnotetext{
${ }^{40}$ For all other items and services, Amazon Pay will assist the customer to resolve the dispute with the merchant but the customer will not be eligible to receive a refund of any part of the purchase price.

41 'Buyer Dispute Program', Amazon Pay (Web Page) <https://pay.amazon.com/us/help/20175 $1580>$.

${ }^{42}$ This is an area which merits further research. See, for example, Anjanette H Raymond, 'A Meeting of the Minds: Online Dispute Resolution Regulations Should Be Opportunity Focused' (2015) 16 University of California Davis Business Law Journal 189, 198; Stefan RM Lancy, 'ADR and Technology' (2016) 27 Australasian Dispute Resolution Journal 168, 173; Kananke Chinthaka Liyanage, 'The Regulation of Online Dispute Resolution: Effectiveness of Online Consumer Protection Guidelines' (2012) 17(2) Deakin University Law Review 251.

${ }^{43}$ Cybersettle (Web Page) <http://www.cybersettle.com/>.
} 
in cases where initially several issues have been at stake but, subsequent to online mediation, the only contention between the parties is monetary.

This type of automated bidding and settlement is suitable for the settling of monetary claims where the liability is no longer disputed. Companies such as Cybersettle in the US have been successful in implementing this technology. ${ }^{44}$ The parties are required to make successive blind bids which remain confidential so as not to prejudice future negotiations. This can overcome parties' fear of revealing bottom lines during the negotiation. Once the bids fall within a certain range, settlement will be proposed for the median amount. This is driven by software and does not require human involvement. Communication applications such as e-mail and web-based platforms are used to support the resolution process. Such a system is cost-effective and prevents escalation of conflicts over small amounts during the negotiation process. Essentially the process involves positional negotiation rather than lengthy interest-based negotiation which could open up a Pandora's Box of conflicting interests and issues which could in turn escalate and further entrench the dispute between the parties. ${ }^{45}$ Despite this, further research should be undertaken to investigate the impacts of power imbalance between parties which can result from differences in financial resources and negotiation skills, as well as online digital literacy. ${ }^{46}$

In summary, the integration of information and communications technologies into ADR processes such as conciliation, negotiation and mediation can augment many of the benefits of traditional offline ADR processes by enabling a quicker, more cost-efficient, flexible and satisfactory process that can produce long-lasting solutions for parties. 'Justice in many rooms', including online ones, is a possibility.

\section{$4 \quad$ Online Arbitration}

The ability to enforce an agreement reached between the disputing parties can provide incentives to participation in the dispute resolution process. Hence it has been argued by Schwarzenbacher that, unlike other ODR methods, online arbitration could provide the parties with a binding solution which could be

\footnotetext{
${ }^{44}$ Cortés (n 24) 65.

45 Positional negotiation focuses on linear concession-making whereby parties move from opening positions in ever-decreasing increments toward a compromise. Negotiations often involve a combination of positional and interest-based negotiation strategy. The latter allows the parties to explore and satisfy interests rather than competing over positions. For this reason negotiation is not a zero sum game.

${ }^{46}$ Frequent users of the system may be able exploit the imbalance of power when bidding against an infrequent user.
} 
enforced in the offline world. ${ }^{47} \mathrm{He}$ argues that, under article VII of the Convention on the Recognition and Enforcement of Foreign Arbitral Awards, the enforcement of online arbitration agreements and the resulting awards are possible in cases where a national law or international treaty or convention permits the recognition and enforcement of arbitration agreements concluded and signed electronically. ${ }^{48}$ Further, given the principle of party autonomy, parties can tailor the proceedings to their specific needs. For example, the parties can agree to adopt a particular set of procedural rules that allow for the use of novel technologies in the resolution process to reduce prohibitive costs, especially in cross-border disputes.

However, despite these potential benefits, online arbitration has experienced a slow growth. There could be several reasons for this. First, offline judicial enforcement arguably defeats the purpose of an online resolution. For this reason Baert has argued that online arbitration awards must be enforced in other ways than through the traditional court system. ${ }^{49}$ Second, there are uncertainties surrounding the enforcement of online arbitration agreements and the resulting online arbitral awards. ${ }^{50}$ For example, the terms and conditions of an agreement might require a consumer to submit to a specific ODR procedure as an exclusive means of resolving a dispute, thereby waiving the right to litigate. Such terms and conditions might not be enforceable, especially where the consumer has had little notice of such terms and has given little meaningful consent to them. ${ }^{51}$

Such pre-dispute arbitration agreements can be refused enforcement, especially in cases involving consumer and electronic contracts. For example, 'in the European Union, electronic merchants ('e-merchants') cannot require the buyer to resolve a dispute through online arbitration, although they are permitted to propose this as an option'. ${ }^{52}$

\footnotetext{
${ }^{47}$ Paul Schwarzenbacher, 'Online Arbitration: A European and US Perspective' (2018) 10 Bocconi Legal Papers 387, 412. See also Philippe R Baert, 'The Potential of Online Arbitration (OARB) in Resolving Disputes at the Lower End of Value: Justice without the State, or State of Injustice' (Master of Laws Thesis, University of Ghent, 2017) 11 <https://lib.ugent. be/fulltxt/RUG01/002/349/376/RUG01-002349376_2017_0001_AC.pdf>.

${ }^{48}$ Schwarzenbacher (n 47).

${ }^{49}$ Baert (n 47) 24.

${ }^{50}$ Cortés (n 24) 69 and Baert (n 47) 13.

${ }^{51}$ Lucille M Ponte, 'Getting a Bad Rap? Unconscionability in Clickwrap Dispute Resolution Clauses and a Proposal for Improving the Quality of These Online Consumer "Products", (2011) 26 Ohio State Journal on Dispute Resolution 119, 123.

${ }^{52}$ Schwarzenbacher (n 47) 422.
} 
In addition, there are 'no universally accepted rules directly governing online arbitration procedures' ${ }^{53}$ and it is also unclear whether the Convention on the Recognition and Enforcement of Foreign Arbitral Awards applies to awards made through online arbitration. ${ }^{54}$

Many of the ODR examples mentioned thus far utilise what Sourdin has termed 'supportive' and 'replacement' technologies. ${ }^{55}$ The central feature of such ODR systems is the involvement of human beings and human intelligence in the planning, managing and decision-making processes. The VCAT's ODR pilot can be viewed in the same light. The online hearing was designed to be the same as an in-person hearing. Parties were able to log into the online platform from their own device at a location which was convenient to them. In addition, documentation could be securely uploaded, stored and made accessible to all parties to the case through the same online portal. The portal also allowed for other parties, such as witnesses, to attend a hearing by logging into the portal. The use of information communication technology is facilitative or supportive in this regard. Offline activities are replicated online to enhance access and allow for flexibility.

The discussion will now turn to ODR systems which are capable of full automation.

\section{Autonomous and Fully Automated}

Although not directly relevant to the VCAT's pilot, there exist more complex automated ODR systems which have the potential to resolve consumer disputes. Autonomous ODR systems might be able to offer problem diagnosis and resolution capabilities that are fully automated using algorithms, legal data analytics and predictors as well as legal artificial intelligence techniques. Such techniques can include, 'text mining, knowledge based self-learning, machine learning and natural language processing, ${ }^{56}$ They can be used to analyse a large amount of 'data with descriptive, diagnostic, predictive and prescriptive analytics tools' ${ }^{57}$ Technology in recent years has been increasing in

\footnotetext{
${ }^{53}$ Ibid 387.

${ }^{54}$ Ibid 412-15.

55 Tania Sourdin, 'Justice and Technological Innovation' (2015) 25 Journal of Judicial Administration 96, 96.

${ }^{56}$ Judith Bennett et al, 'Current State of Automated Legal Advice Tools: Discussion Paper 1', University of Melbourne, Networked Society Institute (Discussion Paper, 2018) 11 $<$ https://networkedsociety.unimelb.edu.au/_data/assets/pdf_file/0020/2761013/2018-NSICurrentStateofALAT.pdf $>$.

${ }^{57}$ Ibid.
} 
sophistication, with 'technologies such as neural networks, natural language generation and social intelligence solutions' being developed, as well as the blockchain technology which allows for transactions to occur with no intermediaries and human involvement. ${ }^{58}$

One significant feature of these more advanced automated technologies is the ability for the machine learning technology to recommend decisions which are not explicitly programmed by a human. Instead, the machines have the capacity to self-learn from data, using statistical reasoning. In such cases, technology supersedes human interaction and artificial intelligence is used to present available alternatives to disputing parties, thus narrowing the issues in the dispute and the differences between the parties. ${ }^{59}$ The systems would be able to identify 'concepts and patterns in the data, form and test hypotheses, and develop recommendations' as a result of their analysis. ${ }^{60}$

The use of such technologies could have a major impact on our justice system, especially if they could be integrated within existing adjudicatory or nonadjudicatory processes. Such systems could allow for a large number of claims to be processed, thus providing access to avenues of dispute resolution for conflicts with similar characteristics. Sourdin argues that the most significant impact is likely to be seen in cases where determinative processes are used. ${ }^{61}$ In addition, the use of pre-designed algorithmic options may eliminate the predispositions associated with human decision making ${ }^{62}$ and potentially result in fairer outcomes for parties. ${ }^{63}$ The data obtained from the systems can be used in three ways: 1) to further monitor the quality of processes and outcomes, 2) to uncover biases and problems in the operation of the algorithms, and 3) in some cases, to allow for dispute prevention altogether. ${ }^{64}$

\footnotetext{
${ }^{58}$ Ibid 12.

59 National Alternative Dispute Resolution Advisory Council, The Resolve to Resolve: Embracing ADR to Improve Access to Justice in the Federal Jurisdiction (Report, September 2009) 73 ('The Resolve to Resolve') <https://www.ag.gov.au/LegalSystem/Alternate DisputeResolution/Documents/NADRAC\%20Publications/the-resolve-to-resolve-embracingadr-improve-access-to-justice-september2009.pdf $>$.

${ }^{60}$ Bennett et al (n 56) 13.

${ }^{61}$ Sourdin (n 55) 101.

${ }^{62}$ For example, Sourdin has mentioned a range of factors that can influence a human judge including: personal values, unconscious assumptions, reliance on intuition, the attractiveness of the individuals involved, and emotion. See Tania Sourdin, 'Judge $v$ Robot? Artificial Intelligence and Judicial Decision-Making' (2018) 41(4) UNSW Law Journal 1114, 1128-9.

${ }^{63}$ Orna Rabinovich-Einy and Ethan Katsh, 'Access to Digital Justice: Fair and Efficient Processes for the Modern Age' (2017) 18(3) Cardozo Journal of Conflict Resolution 637, 648.

${ }^{64}$ Ibid.
} 


\section{LESSONS FROM OTHER JURISDICTIONS}

The ODR model which has been recommended by the 2016 Victorian government Access to Justice Review for adoption by VCAT has many similarities with the model used by the British Columbia Civil Resolution Tribunal. First of all, it encourages early dispute resolution by empowering members of the public by giving them relevant information on their rights and obligations. It then allows parties to resolve their disputes, facilitated by qualified ADR specialists. ${ }^{65}$ The evident desire to imitate traditional ADR methods is perhaps grounded on the assumption that such methods would be appropriate for small value claims where the lack of face-to-face communication would be of minor importance and where legally sound and fair court-based decisions may seem impractical or unsatisfactory for parties.

\section{A British Columbia}

The CRT offers ODR for strata property disputes (with no maximum value) and small claims disputes to the value of CAD 5000. ${ }^{66}$ Such disputes can concern debt or damages claims, recovery of personal property, personal injury and specific performance of agreements involving personal property or services. ${ }^{67}$ This online tribunal is one rare example of a permanent, publicly administered ODR system which resolves offline disputes. The ODR process begins with provision of information and problem diagnosis. Subsequently, it progresses to party-to-party negotiation and, where that fails, the process turns into a facilitated ADR. If parties are still unable to reach an agreement, adjudication will take place. ${ }^{68}$

The first stage involves an expert system called Solution Explorer. An expert system is computer software that uses some amount of AI in the form of causal and defined logic codes to simulate the judgment and behaviour of a human ${ }^{69}$ or an organisation with expert knowledge and experience in a particular field. ${ }^{70}$ This AI is also often referred to as simple or rules-based AI. System designers

\footnotetext{
${ }^{65}$ Access to Justice Review (n 2) 277.

${ }^{66}$ Civil Resolution Tribunal [British Columbia] (n 4).

67 'Fees', Civil Resolution Tribunal (Web Page, 2019) <https://civilresolutionbc.ca/resources/crtfees/>.

68 Shannon Salter, 'Online Dispute Resolution and Justice System Integration: British Columbia's Civil Resolution Tribunal' (2017) 34 Windsor Yearbook of Access to Justice 112, 114.

${ }^{69}$ Philip Leith, 'The Rise and Fall of the Legal Expert System' (2010) 1(1) European Journal of Law and Technology <http://ejlt.org/article/view/14>.

${ }^{70}$ Bennett et al (n 56) 13.
} 
will obtain expert knowledge from human experts and encode that knowledge into rules which can be applied based on the information obtained from the users. ${ }^{71}$ The systems will prompt the users to answer several questions before responses are produced, based on a decision-tree analysis.

In the context of ODR, an expert system such as the Solution Explorer is used to encourage early dispute resolution by providing useful information for the parties regarding the nature of their dispute to help them make informed choices about how to resolve it. For example, such a system can determine the eligibility of claims under certain legislation. Any effective ODR platform should include such a first-line dispute avoidance process. According to the CRT's snapshot for October 2018, a total of 48,574 Solution Explorer explorations were carried out, with 29,593 explorations concerning small claims and 18,981 concerning strata property. ${ }^{72}$

In practical terms, the Solution Explorer system uses interactive questions and guided pathways to provide potential disputants with free, tailored legal information. It also provides tools and resources to enable self-help, such as template letters (for example, to ask for a hearing or to send to the disputants' owners' corporations) to help disputants resolve disputes consensually.

If a person is unable to resolve their dispute consensually after accessing Solution Explorer, the next step is to start a claim. This is the second stage in the ODR process. The parties are not required to re-enter all the relevant information as the system carries the information initially entered through to the subsequent stages. Moreover, the ODR process 'incorporates relevant parts of the Tribunal's rules on an as-needed, when-needed basis, to avoid overwhelming parties with inapplicable rules'. ${ }^{73}$

Once a claim is commenced, facilitators will attempt to facilitate consensual resolution of the dispute. This is the third stage of the ODR Process. This stage is intended to be flexible and responsive. ${ }^{74}$ The facilitators can use a variety of tools to help parties settle their claims. The facilitators are required to have strong mediation experience and skills to ensure that they can help parties reach a consensual agreement, wherever possible. All settlement communications are confidential and are not disclosed to the Tribunal members. If the parties reach an agreement, the Tribunal member can convert the agreement into a binding

\footnotetext{
${ }^{71}$ Ibid.

72 'CRT Statistics Snapshot: October 2018', Civil Resolution Tribunal (Web Page) $<$ https://civilresolutionbc.ca/crt-statistics-snapshot-september-2018-2/>.

${ }^{73}$ Salter (n 68) 120.

${ }^{74}$ Ibid 121.
} 
order which can be enforced in court. ${ }^{75}$ If the parties reach an agreement, the facilitator can ask a tribunal member to convert the agreement into a binding order of the tribunal, which can be enforced in court, without the parties having to sue for a breach of the agreement. The Tribunal 'anticipates that the facilitation stage could resolve up to 70 percent of disputes' ${ }^{76}$

If the parties are unable to reach an agreement, the dispute can progress to the adjudication stage. The facilitator will continue to play a neutral role in preparing the parties for this stage, for example through narrowing issues and organising their claims. During the adjudication stage, a Tribunal member with relevant expertise will hear the parties' evidence and submissions and make a binding decision. Participants can seek legal assistance throughout the process and, if a hearing becomes necessary, a party will be able to request permission to have a lawyer to represent them. Hearings will generally take place via telephone or videoconferencing.

The end-to-end process is intended to take around ninety days for most cases and the average total cost to the parties is about CAD $200 .^{77}$ The fees are staged and hence parties may not have to pay the full fees if they are able to resolve their disputes early in the process. More importantly, the fees are set at a level which will arguably deter frivolous claims. ${ }^{78}$ Salter observes that, by leveraging technology, the Tribunal 'democratizes access to dispute resolution services by connecting the public, wherever they may live, with expert facilitators and tribunal members' ${ }^{79}$ If VCAT is to implement a similar system, then adequate funding must be made available through the design, implementation and evaluation stages.

\section{B The United Kingdom}

In the United Kingdom, Lord Justice Briggs's 'Civil Courts Structure Review' recommends an online court for claims up to $£ 25,000{ }^{80}$ This will arguably be a most radical and important structural change to the civil courts system which

\footnotetext{
${ }^{75}$ Ibid.

${ }^{76} \mathrm{Ibid}$.

${ }^{77}$ Ibid.

${ }^{78}$ Ibid.

${ }^{79}$ Ibid $120-1$.

${ }^{80}$ Lord Justice Briggs, 'Civil Courts Structure Review', Courts and Tribunals Judiciary (Web Page, 27 July 2016) <https://www.judiciary.gov.uk/civil-courts-structure-review/>.
} 
will enable disputes of small value and complexity to be resolved online. It will aim to improve access to justice for people and small businesses.

It is recommended by Lord Briggs that the online court should offer three stages of dispute resolution. ${ }^{81}$ Stage 0 would provide parties with vital information about treating litigation as a last resort and the sources of affordable or free advice; it could also provide summaries of the essential legal principles. Stage 0.5 would allow parties to discuss their matters with each other to determine the nature of the dispute which the court needs to resolve.

Stage 1 triage would involve a largely automated and interactive online process which would enable the identification of the issues and the requirements for provision of documentary evidence. The online portal would assist the parties to develop a simplified pleading that would be capable of being understood by their opponent and by the court. ${ }^{82}$ In many undisputed civil claims, the court is resorted to for enforcement rather than for dispute resolution. In such cases, the system would allow represented parties to by-pass the full Stage 1 triage. ${ }^{83}$ This would save the parties time and costs.

If Stage 1 were not by-passed, the subsequent step would be likely to involve the use of ADR methods such as mediation. This would be Stage 2 of the process. If parties were unable to reach an agreement at this stage, they could proceed to Stage 3 and obtain resolution by judges. The court might choose to resolve the matter based on the documents submitted or after communicating with the parties via telephone or video. Face-to-face hearings, if used, would be restricted to resolving particular issues in the dispute. ${ }^{84}$

Menashe argues that the introduction of such an online court would act as 'the first step toward accommodating the court system to the innovative reality of the Internet Age, in a manner which is both systematic and controlled' ${ }^{85}$

\footnotetext{
${ }^{81}$ Lord Justice Briggs, Civil Courts Structure Review: Final Report (July 2016) 1, 58-60 $<$ https://www.judiciary.uk/wp-content/uploads/2016/07/civil-courts-structure-review-finalreport-jul-16-final-1.pdf>.

${ }^{82}$ Ibid 59.

${ }^{83}$ Ibid.

${ }^{84}$ Ibid.

85 Doron Menashe, 'A Critical Analysis of the Online Court' (2018) 39(4) University of Pennsylvania Journal of International Law 921, 922.
} 


\section{The United States}

In the United States, a relevant example is Modria's ${ }^{86}$ property tax assessment dispute settlement service which has been adopted by several local government jurisdictions including Durham County, Fulton County, North Carolina, Alachua County, Florida, Orleans Parish, Louisiana and Davidson County, Tennessee ${ }^{87}$ It provides services which enable property owners appealing property tax assessment to have their cases reviewed and resolved through a combination of online and offline procedures. This tax assessment appeals process goes beyond internalising online dispute resolution for organisational communication and interaction, and constitutes the first case of institutionalisation of ODR as a significant means of providing government services to the public.

In addition, Utah pioneered the adoption of an ODR system in its small claims court in September 2018. ${ }^{88}$ The court has jurisdiction over claims of USD 11,000 or less, and the parties are almost always both unrepresented. Typically, only two parties are involved and the majority of the cases are debt collection cases. ${ }^{89}$ The system is capable of handling an entire dispute online, as opposed to only a discrete part of a dispute..$^{90}$ According to the Utah Supreme Court Justice, Deno Himonas, the introduction of this system is grounded in the Court's commitment to access to justice and its desire to remain relevant in a changing world. ${ }^{91}$ According to his Honour, the goals that have been set and against which the success of the ODR system will be measured include:

access to justice ... simple, quick, inexpensive and easily accessible justice; individualized assistance and information that is accessible across a multitude of electronic platforms; [the ability of] parties to participate whenever they want .... [the lowering of] costs associated with resolving our small claims disputes and [encouragement and assistance] in the settlement and resolution of those disputes. ${ }^{92}$

\footnotetext{
${ }^{86}$ Modria (Web Page) <https://www.tylertech.com/products/modria>. Modria is a purpose-built ODR platform which can be adapted to the needs of the particular private or public dispute resolution bodies.

87 For example, Fulton County Board of Assessors Resolution Center (Web Page) $<$ https://fultoncounty.modria.com/>; Ohio Board of Tax Appeals Resolution Center (Web Page) <https://ohio-bta.modria.com/>.

${ }^{88}$ Himonas (n 6).

${ }^{89}$ Ibid 881.

${ }^{90}$ Ibid.

${ }^{91}$ Ibid.

${ }^{92}$ Ibid.
} 
In addition, the statutes and the rules of procedure will be amended as necessary to allow for the ODR system to operate..$^{3}$

The complete ODR model which was developed in Utah includes three stages: 1) education and information (utilising an expert system), 2) facilitated selfresolution through mediation, and 3) adjudication with the choice of online or live hearing. The parties also retain a complete de novo right of appeal to the District Court.

The design of the system is similar in nature to that of the British Columbia Civil Resolution Tribunal. At the front end, an expert system will provide useful information and self-help resources for parties, as well as evaluate the nature of the claims. This encourages early dispute resolution between the parties and reduces information asymmetry. The parties will be able to communicate using the online communication platform where all parties interact in real time to resolve their dispute without intervention from the Court. In addition, there will be trained facilitators who are able to mediate and answer basic questions as well as provide, in Justice Deno Himonas's view, some limited legal advice on the process ${ }^{94}$ They will also be able to help parties to build a settlement document if the parties choose not to do this themselves. ${ }^{95}$

If, after facilitation, the parties are still unable to reach a settlement, the facilitator will assist them with trial preparation. ${ }^{96}$ For example, the facilitators can provide a trial preparation document which will narrow the issues based on parties' description of what they have been able to solve and what remains unresolved. The parties can upload documents they think are appropriate with the guidance of the facilitator. The judge will have the discretion to hear the matter live or to simply make the decision based on what the parties have submitted electronically. ${ }^{97}$

It is anticipated that collection capabilities will be available through the same platform in the second stage. ${ }^{98}$ It is also anticipated that an evaluation of the project will be undertaken to measure the success of the system against its

\footnotetext{
${ }^{93}$ Ibid.

${ }^{94}$ Ibid 882.

${ }^{95}$ Ibid 893.

${ }^{96}$ Ibid 894.

${ }^{97}$ Ibid.

${ }^{98}$ Ibid.
} 
goals. If the evaluation produces a positive result, the system will be rolled out across the State in all small claims cases. ${ }^{99}$

\section{Small Civil Claims and VCAT}

Having discussed the different types of ODR system and how different jurisdictions have adopted them, this article will now analyse the system which has been recommended by the Access to Justice Review for adoption in VCAT.

As a modern tribunal, VCAT was established to provide efficient and costeffective dispute resolution processes. It can hear matters of low monetary value, such as small claims (a claim of AUD 15,000 or less) and owners corporation matters as well as multi-party disputes with complex facts and high monetary value, such as planning, local government and professional disciplinary disputes. In addition, it can hear disputes that can have significant non-monetary consequences for the parties, such as residential tenancy, antidiscrimination and guardianship matters.

According to VCAT's Annual Report 2016-2017, since 1 July 2016, there had been a $29 \%$ overall increase in civil claims over the year. Of relevance to this article is VCAT's role in resolving small civil claims. The report listed a $28 \%$ increase in the lodgment of small civil claims from 5,555 applications in 20152016 to 7,138 in $2016-2017 .{ }^{100}$ In the resolution of such claims, VCAT seeks to enforce consumer rights and provide redress, as well as deterring against violation of those rights. It seeks to do so in a manner that is affordable and timely for the consumers. ${ }^{101}$ As noted in the 2016 Victorian government Access to Justice Review, the introduction of an ODR system can help promote these objectives. ${ }^{102}$ It will serve as an introduction of ODR in Victoria. Significant funding announcements have since been made by the Victorian government, including an AUD 4.55 million investment in VCAT's digital strategy to help modernise its systems and deliver better online services to its customers. ${ }^{103}$

\footnotetext{
${ }^{99}$ Ibid.

100 VCAT, Annual Report 2016-2017: Embedding Change and Efficiencies (30 November 2017) 90, 53-4 ('VCAT Annual Report 2016-2017') <https://www.vcat.vic.gov.au/resources/annualreport-2016-17>.

${ }^{101}$ Access to Justice Review (n 2) 245.

102 Ibid.

${ }^{103}$ VCAT Annual Report 2016-2017 (n 100) 11.
} 


\section{A Integration of Information and Communications Technology in VCAT}

The introduction of an ODR system in VCAT is aligned with VCAT's new four-year digital strategy, set in 2017, to deliver more and better online services. In its 2016-2017 Annual Report, VCAT stated that '[t]he starting point for any VCAT service is that people want to interact with [VCAT] by digital methods — online and by email'. ${ }^{104}$

Some relevant examples of the expansion of the use of information and communication technology are the development of online forms and the progressive rolling out of the e-lodgment capability. ${ }^{105}$ The Report mentions that more people than ever chose to lodge applications online in the year 20162017 but that functionality issues with the processes emerged. ${ }^{106}$ For example, 65 online lodgments of civil claims took place in 2016-2017 as compared to 38 in the previous year. ${ }^{107}$ However, due to the functionality issues, VCAT concluded that efficiency gains were limited. ${ }^{108}$ Similarly, the Report reveals that some benefits and efficiencies were realised from the introduction of elodgment for active Transport Accident Commission cases but that uptake was low from legal firms as the system did not fully integrate with their systems and preferred payment methods. ${ }^{109}$ VCAT is continuing to develop an online system to help people manage guardianship applications. ${ }^{110}$

VCAT has also introduced an online platform for the Residential Tenancies List. The Residential Tenancies Hub is accessible to tenants, landlords and estate agents via the VCAT website. ${ }^{111}$ It can be used to create notices, make applications to VCAT, pay fees and search for previous notices and applications. ${ }^{112}$

\footnotetext{
${ }^{104}$ Ibid 24.

${ }^{105}$ Ibid 25.

${ }^{106}$ Ibid.

${ }^{107}$ Ibid.

${ }^{108}$ Ibid.

${ }^{109}$ Ibid.

${ }^{110}$ Ibid.

${ }^{111}$ Ibid.

112 Ibid.
} 


\section{B Recommended ODR System for VCAT}

The Access to Justice Review proposed a three-stage ODR system as illustrated in the following diagram.

Figure 1: Potential Stages of an Online Dispute Resolution System ${ }^{113}$

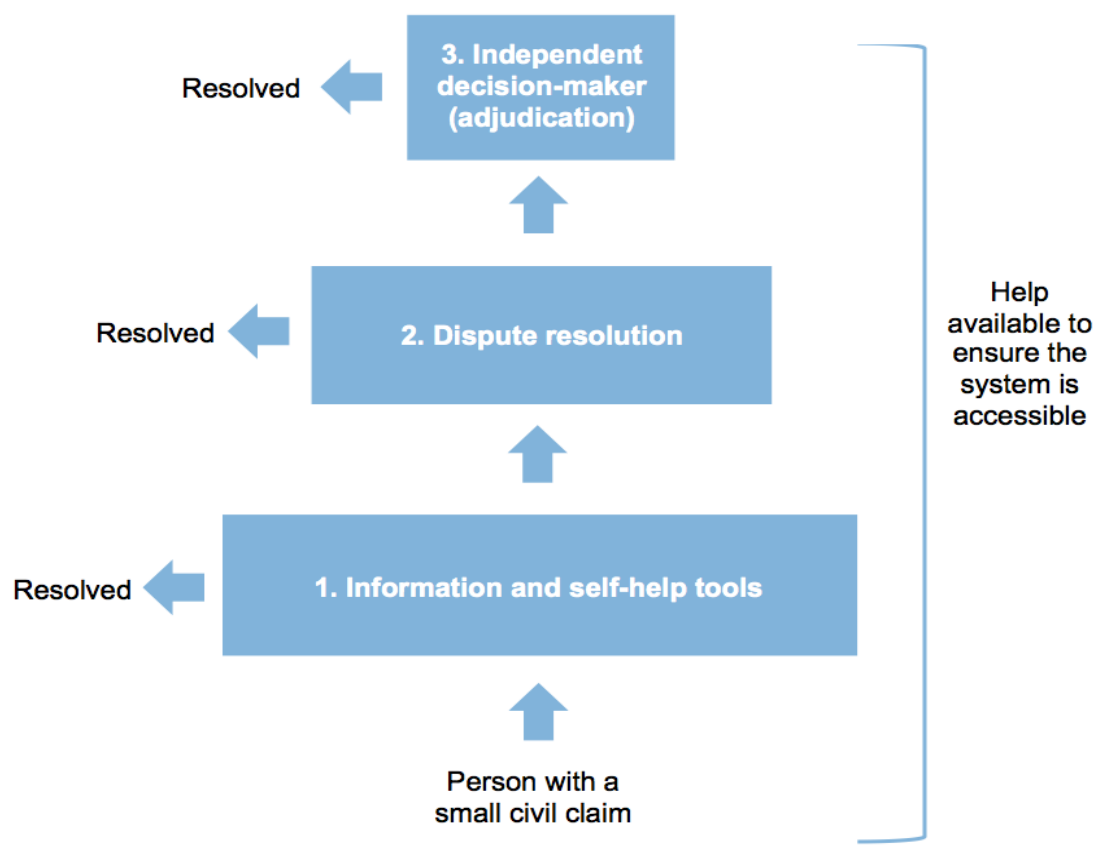

The different stages closely resemble those currently utilised by the British Columbia Civil Resolution Tribunal. The Review proposed that Stage 1 should provide general information and identify potential next steps in relation to resolving a small civil dispute. ${ }^{114}$ In addition, it was recommended that this stage should include some of the following:

\footnotetext{
${ }^{113}$ Access to Justice Review (n 2) 278. The Figure is reproduced pursuant to a Creative Commons Licence: <creativecommons.org/licenses/by/3.0/au>. Attribution of authorship is hereby made to the State of Victoria. The present author has made no changes to the Figure.

${ }^{114}$ Ibid 277.
} 
- the provision of targeted information to people in response to common questions;

- the provision of information in different media, for example, text-based information as well as audio and videos in different languages;

- the facility for users to download, email or print documents, templates and resources;

- $\quad$ assistance to people in gaining an understanding of the merits of their case and their options to resolve the dispute; and

- the empowerment of people to take action to resolve their dispute. ${ }^{115}$

If parties cannot resolve their dispute at Stage 1, the Review recommended that parties continue to Stage 2. In this stage, the resolution of the parties' dispute would be facilitated by qualified ADR specialists who would explore the possibility of a consensual agreement between the parties. Facilitators should be able to choose the most appropriate form of communication with the parties, including online communication, e-mail, text message, video-conference, telephone call, letter or in-person communication. Further, if the parties reach an agreement, there should be provision for the agreement to be approved by a VCAT member and converted into a binding order of VCAT. ${ }^{116}$

In the event that the parties cannot reach an agreement at the second stage, the facilitator should assist parties in their preparation for Stage 3 by helping them to refine the issues and to organise their claims. Stage 3 would involve adjudication by a VCAT member. An additional fee may apply at this stage. Parties would be able to continue to use the online system to submit a claim and supporting documents. VCAT members would then consider the evidence and hear from the parties using whatever communication method is most appropriate, including e-mail. They might hold hearings by phone, videoconference, or even in person. ${ }^{117}$ The decisions made under the online system should be enforceable in any court and should be appealable on judicial review

\footnotetext{
115 Ibid.

${ }^{116}$ Ibid 278. It will be of interest to analyse the implication of the integration of such an ODR system on the use of ADR in VCAT. Currently almost all matters in the Civil Division that have no monetary value or are valued at AUD 100,000 or more are referred to mediation or compulsory conferencing in an effort to resolve the matter or narrow the dispute prior to hearing.

${ }^{117}$ Ibid.
} 
grounds. The Review also recommended that members be subject to the same procedural fairness requirements as govern VCAT hearings generally. ${ }^{118}$

The article will now focus on the actual VCAT ODR pilot.

\section{The VCAT ODR Pilot}

The pilot focused on small civil claims and, more specifically, claims made by small businesses. During the planning stage, different user personas were created, based on VCAT's different client groups, to identify the dispute resolution needs of the different groups and their typical resolution journey in VCAT. ${ }^{119}$ The hypothesis behind the pilot was that, if VCAT introduced ODR, the Victorian community would experience improved access to justice. ${ }^{120}$ The funding for the pilot was initially AUD 800,000 for three months preparation. ${ }^{121}$ Additional funding was secured to run the pilot at the end of that preparatory period.

The pilot focused only on a discrete part of dispute resolution, namely online adjudication (Stage 3). This means that it did not seek to provide end-to-end ODR for parties. This was mainly due to time constraints as the pilot was only for a one-month period. There were 65 cases and 71 parties involved. ${ }^{122}$ The parties attended the hearing online, using video conferencing facilities on their own personal devices in a location that was convenient to them. The parties were also able to upload documents to the online platform prior to hearing. In implementing this pilot, VCAT adopted the Agile methodology. Such method focuses on incremental development and trialling of the different parts of the system.

The trialling of early prototypes, along with a strong focus on human-centred design principles, is a trend that is increasingly visible in the public sphere when it comes to innovating legal services to the public. ${ }^{123}$ According to Hagan, 'the goal is to act quickly and to build things in order to test hypotheses rather than

\footnotetext{
${ }^{118}$ Ibid.

119 VCAT ODR Pilot Team, 'VCAT ODR Pilot: A Case Study', ODR: The State of the Art International Symposium (Symposium Paper, 22 November 2018) ('VCAT ODR Case Study') <https://www.odrmelbourne.com.au/>.

${ }^{120}$ Ibid.

${ }^{121}$ Ibid.

122 Ibid.

${ }^{123}$ Margaret D Hagan, 'A Human-Centered Design Approach to Access to Justice: Generating New Prototypes and Hypotheses for Intervention to Make Courts User-Friendly' (2018) 6(2) Indiana Journal of Law and Social Equality 199, 199.
} 
merely speculating about what new idea will work best'. ${ }^{24}$ Through the implementation of this pilot, feedback was obtained from all relevant stakeholders, including the intended users rather than only from experts or system professionals. This human-centred methodology should continue to be utilised in order to ensure that innovations are truly enhancing access to justice.

The concrete outcomes from the pilot included a higher respondent participation rate than is normal in small claim dispute resolution, greater convenience for parties, time saving and easier submission of evidence. ${ }^{125}$ Despite these positive outcomes, further research is needed to investigate the potential issues which can arise where the dynamic of the dispute resolution process is new. They may arise due to parties not being physically present in the same hearing room, as in the case of online adjudication or mediation, or due to the use of online negotiation. The change in dynamic can be caused by lack of posture and visual cues or indirect non-verbal communication cues, possible erosion of the sense of the immediacy and importance of the dispute and its resolution, a lack of the sense of warmth and empathy or a 'personal touch' between the parties, or the inability to express emotions through a combination of verbal and non-verbal communication cues such as voice and tonality. ${ }^{126}$

The lessons and experience gained from this pilot will, it is hoped, inform the development of a more encompassing ODR system in VCAT in line with the recommendations from the Access to Justice Review.

\section{The NCAT ODR Pilot}

In New South Wales, the NSW Civil and Administrative Tribunal ('NCAT') similarly engaged in a pilot program in late 2014 to provide an online option for the resolution of consumer disputes, focusing on lower value claims under AUD 5,000. This was a 13-week pilot program conducted on an 'opt in' basis. ${ }^{127}$ Participants were able to access the pilot via a secure online portal 24

\footnotetext{
${ }^{124}$ Ibid 203.

125 'VCAT ODR Case Study' (n 119).

${ }^{126}$ Claire Holland and Donnalee Taylor, 'Was That Said with a Smile? Factors Influencing Effective Online Negotiations' (2016) 27 Australasian Dispute Resolution Journal 103, 1056.

127 The Hon Justice Robertson Wright, Civil and Administrative Tribunal of NSW, Annual Report 2014-2015 (2015) 79 ('NCAT Annual Report') <https://www.ncat.nsw.gov.au/ Documents/ncat_annual_report_2014_2015.pdf>.
} 
hour per day, seven days a week. ${ }^{128}$ They could discuss information about their dispute in a structured way online. Further, the automated software guided parties through different stages including: issue identification, joint development of solutions, the generation of a negotiated agreement, or a withdrawal. It was designed to assist parties 'to focus on the issues they wished to have resolved and to lead them to outcomes which would be acceptable to both sides so that, where possible, a negotiated agreement could be reached'. ${ }^{129}$

Where an agreement was reached, the parties could seek an enforceable order from the Tribunal to give effect to their agreement. Where an agreement was not reached, or if either party chose not to use ODR, the parties withdrew from the online process and the dispute was listed for hearing before the Tribunal to be determined in the usual way. Unfortunately, very few reports on the success of the pilot can be found. According to the NCAT Annual Report 2014-2015, ' $[t]$ he results of the pilot suggested that ODR should be considered further as a means of enhancing the services provided by NCAT and improving the efficiency of the Tribunal's operations'. ${ }^{130}$

Justice Robertson Wright in his role as the President of NCAT commented:

The pilot showed that such a mechanism can operate to fill a gap in the dispute resolution process by helping applicants in consumer claims overcome difficulty in approaching suppliers, sometimes large corporations, by allowing consumers to do so in their own time and on their own terms in order to discuss resolution of their issues. On the other hand, the suppliers themselves benefitted [sic] from early and effective contact with consumers giving them the opportunity of avoiding the time and expense involved in responding to the first contact at a hearing in the Tribunal. ${ }^{131}$

\footnotetext{
${ }^{128}$ Robertson Wright, 'A New Approach to Civil Disputes' (Speech delivered at the Newcastle Chapter of the Resolution Institute - ADR Forum, Newcastle, 12 August 2016) 23 <http://www.supremecourt.justice.nsw.gov.au/Documents/Publications/Speeches/2016\%20Sp eeches/Wright_120816.pdf>.

${ }^{129}$ Ibid.

${ }^{130}$ NCAT Annual Report (n 127) 28.

${ }^{131}$ Wright (n 128) 23-4.
} 


\section{IMPLICATIONS OF ODR}

\section{A Improving Efficiency and Access to Justice}

VCAT has highlighted similar potential benefits of the introduction of an ODR platform to those mentioned by Justice Robertson Wright. ${ }^{132}$ They include access to a secure online portal that can be used at the party's convenience and a means of exchanging information with the other party in a safe and confidential environment. They also include the removal of the need to take time off work to attend a VCAT hearing or mediation. Such a platform can also improve access to VCAT for people in regional and remote areas of Victoria. ${ }^{133}$ Parties can conveniently and securely upload, store and access documentation through the online portal. ${ }^{134}$

Moreover, the introduction of such an online platform can potentially assist parties who have no access to legal representation or other legal assistance, who may think that their dispute is too complex or time consuming to resolve, or who may be unaware of their legal rights and the relevant enforcement mechanisms. The Productivity Commission has estimated that approximately $15 \%$ of the Australian population have unmet legal needs which can have a moderate to severe impact on their daily life. ${ }^{135}$

The online platform could also improve access to dispute resolution for people from non-English speaking backgrounds if the platform can be translated into their preferred language. This may help resolve issues relating to access to interpreters and bilingual assistance that might not otherwise be available at VCAT locations. ${ }^{136}$ Such technology can also be helpful in providing people with visual or hearing disabilities with remote access to dispute resolution through the use of screen readers or sign language support. ${ }^{137}$ Another potential benefit of ODR is the provision of a safe dispute resolution environment in cases where violence between disputants is a real possibility. Rogers contends that ODR 'presents promising possibilities for reaffirming victim autonomy,

\footnotetext{
132 'Access to Justice Review 2016: VCAT Submission', Victorian Civil and Administrative Tribunal (Submission, 2016) 11 <https://s3.ap-southeast-2.amazonaws.com/hdp.au.prod.app. vic-engage.files/9014/8609/4198/Submission_34_-_Victorian_Civil_and_Administrative_ Tribunal.pdf>.

${ }^{133}$ Ibid.

134 'VCAT ODR Case Study' (n 119).

${ }^{135}$ Access to Justice Review (n 2) 62.

136 James E Cabral et al, 'Using Technology to Enhance Access to Justice' (2012) 26(1) Harvard Journal of Law and Technology 243, 262-4.

${ }^{137}$ Ibid.
} 
increasing victim safety, and reducing the effect of harmful gender and racial norms in the judicial process'. ${ }^{138}$

This article argues that equal access to the ODR platform is crucial. Careful attention must be given to avoiding the marginalisation of users because of their lack of technology literacy or 'digital fluency', ${ }^{139}$ lack of legal representation, geographical location or disability.

Except in cases involving the automatic right to representation or where supportive attorney appointments are made under the Powers of Attorney Act 2014 (Vic), parties are usually encouraged to represent themselves in VCAT. Therefore, technology must be implemented in such a way as not to disadvantage those without legal representation. Usability and access issues which are unique to self-represented parties must be fully considered. For example, parties may be accessing the platform using public computers available at libraries or community legal centres. For this reason special provisions must be made to protect their private information and to allow them to create and save incomplete forms in a safe and user-friendly platform. It must, however, be noted that the same features that make a particular form or document friendly for unsophisticated users may make it unfriendly for frequent, more sophisticated, users. For this reason the reasonable needs of both types of users will play a role in influencing the system design.

Furthermore, since the platform is supposed to increase flexibility and access unconstrained by physical and geographical barriers, the design must anticipate that there may be little on-site support for parties who decide to access the system remotely instead of at VCAT or community legal centres. The same can be said for parties who would like to appear through videoconference but are not able to do so due to technological challenges. In such cases, the availability of support as well as alternative services must be ensured.

Similarly, it is also important that the platform does not create additional barriers for persons with disabilities. ${ }^{140}$ To encourage its adoption, adequate

\footnotetext{
${ }^{138}$ Sarah Rogers, 'Online Dispute Resolution: An Option for Mediation in the Midst of Gendered Violence' (2009) 24(2) Ohio State Journal on Dispute Resolution 349, 379.

139 Emily Wang, Michael D Myers and David Sundaram, 'Digital Natives and Digital Immigrants: Towards a Model of Digital Fluency' (2013) 5(6) Business \& Information Systems Engineering 409, 410.The term was used to conceptualise a user's technological adeptness.

${ }^{140}$ See, eg, Carol Brennan et al, 'Consumer Vulnerability and Complaint Handling: Challenges, Opportunities and Dispute System Design' (2017) 41(6) International Journal of Consumer Studies 638; Yvette Maker et al, 'From Safety Nets to Support Networks: Beyond Vulnerability in Protection for Consumers with Cognitive Disabilities' (2018) 41(3) University of New South Wales Law Journal 818.
} 
training and education in the use of the platform will need to be provided to the court or tribunal officers, both through online methods and physically, in the court or tribunal building. The training may need to be done on a regular basis in order to capture first-time users and those who do not use the platform frequently (the so called 'digital immigrants'). ${ }^{141}$ The capacity of users to adapt to different communication media and their online communication literacy will have an impact on the effectiveness and success of the ODR processes.

VCAT would also need to be committed to ensuring the uniformity, standardisation and simplification of online forms and procedures to increase access to justice. Different users' needs and abilities would need to be carefully considered in this process. Methodologies such as human-centred design can be used to achieve this. In addition to being used to improve other professional and government services, human-centred design is also increasingly being used and adapted in the legal domain. ${ }^{142}$ The methodology has as its starting point 'a fundamental concern for user experience combined with an experimental and iterative approach to developing new solutions'. ${ }^{143}$ 'It posits that the best way to evaluate existing offerings and to create new, better ones is to focus on the needs, values, and aspirations of the people who are the target audience of the offering. ${ }^{\text {" }} 44$ For example, Clarke and Borys propose that courts invest in a usability analysis to gauge their users' needs, desires and abilities, as well as their experience, in order to identify areas for improvement. They propose that users be allocated to different service levels, each with appropriate support. ${ }^{145}$ It is argued that such analysis, which takes into account parties' goals and dispute characteristics as well as their needs and interests, is key to ensuring a match between particular disputes and suitable ODR processes.

Such analysis was undertaken by VCAT in the planning stage of the pilot. VCAT found that, in cases involving small or medium-size businesses with multiple small monetary claims, such as those arising from customer debts, the use of a streamlined online platform can facilitate more efficient and costeffective dispute resolution. This client group was identified as the group that often recovered only $30 \%$ of the amount of their claims after having their matters resolved. ${ }^{146}$ Hence, VCAT wanted to test whether the introduction of

\footnotetext{
${ }^{141}$ Wang, Myers and Sundaram (n 139).

${ }^{142}$ Hagan (n 123) 200.

${ }^{143}$ Ibid.

${ }^{144}$ Ibid 202.

${ }^{145}$ John A Clarke and Bryan D Borys, 'Usability Is Free: Improving Efficiency by Making the Court More User Friendly', National Centre for State Courts (2011) 76, $79<\mathrm{https} / / / \mathrm{ncsc}$. contentdm.oclc.org/digital/collection/ctadmin/id/1844/>.

146 'VCAT ODR Case Study' (n 119).
} 
an ODR platform could help reduce the costs and inefficiencies often experienced by this group.

Another significant benefit of submitting to a public or judicially-supported ODR platform is that parties will receive a binding order from the tribunal which will give effect to the agreement reached. The parties will have to agree to abide by a set of procedural rules and laws. For example, in relation to small claims, under the British Columbia Civil Resolution Tribunal Act, a Tribunal's order may be enforced in the British Columbia Provincial Court if the order is either a consent resolution order or a final decision. ${ }^{147}$ When the Tribunal's order is filed with the Provincial Court, it has the same force and effect as if it were a judgment of the Court. The enforcement procedures within the Court's jurisdiction will be applicable. ${ }^{148}$ With the availability of such enforcement and appeals mechanisms, such a system introduces a controlled and systematic endto-end dispute resolution process.

\section{B Allowing for Gathering of Important Data}

A public ODR system can also be used to support the collection and sharing of data and information about systemic issues, trends and patterns to enable the regulators to identify and address systemic consumer issues. De-identified data collected might be shared with Consumer Affairs Victoria to support its policy, enforcement and compliance functions. The Victorian Civil and Administrative Tribunal Act 1998 (Vic) should be amended to expressly permit the sharing of information between the Victorian government and VCAT. ${ }^{149}$ The use of such data may deter and alter certain types of predatory behaviour by some traders, thereby protecting consumers and mitigating the potential for similar disputes in the future. Moreover, recurring dispute patterns can be identified, and complaints can be better categorised. In this way, the ODR pilot can be used to facilitate dispute avoidance in addition to dispute resolution. Rabinovich-Einy and Katsh have commented that:

While dispute resolution theory has traditionally been more focused on fullblown disputes and what is happening 'downstream', the capability to obtain information from persons or groups who do not yet perceive themselves as parties is a valuable by-product of enhanced communications capabilities and, hopefully, a contributor of much more effective dispute prevention strategies. Technology allows those who offer dispute resolution

\footnotetext{
${ }^{147}$ Civil Resolution Tribunal Act, SBC 2012, ch 25, s 58(1).

148 'After a CRT Decision', Civil Resolution Tribunal Processes (Web Page) <https://civil resolutionbc.ca/how-the-crt-works/how-the-process-ends/>.

${ }^{149}$ Access to Justice Review (n 2) 279.
} 
services on- and offline to systematically study patterns of disputes and the effectiveness of avenues for addressing them due to the ease of gathering data and analyzing it through multiple lenses on an ongoing basis. ${ }^{150}$

In its 2009 report titled The Resolve to Resolve: Embracing ADR to Improve Access to Justice in the Federal Jurisdiction, the National Alternative Dispute Resolution Advisory Council commented that 'ODR's versatility and flexibility can support conflict avoidance and may operate as a first-line dispute resolution process that potentially offers fast, simple and cost-efficient resolution'. ${ }^{151}$

However, in order to promote trust in its users, it is important that adequate safeguards exist to protect the privacy of information stored in the platform. Parties who access the platform off-site and in public spaces must be informed of the existence of privacy risks and ways to mitigate such risks. More importantly, the use and analysis of data, including sensitive personal forensic data, may give rise to security and privacy breaches. Therefore, it is important that access to forensic information be balanced against the protection of personal rights. This is further analysed under the next heading.

\section{Values and Justice Discourse}

If ODR is to further penetrate the public sphere, an analysis of the impacts that it will have on values such as legal validity as well as transparency and accountability will need to be undertaken. Different ODR systems may give rise to different issues and a highly automated system is likely to give rise to more serious issues than online systems which mirror traditional dispute resolution processes, such as the recent VCAT ODR pilot.

An ODR platform must not only improve access to justice; it must also be designed to encourage the appropriateness and neutrality of substantive outcomes in the case. This means that if VCAT or other tribunals intend to implement end-to-end ODR systems, the judicial officers — as implementers of the platform - must strive to ensure that the legal work is done comprehensively. Further, where required, parties should be encouraged to obtain additional help so that they can fully understand difficult legal or business concepts and have their documents reviewed prior to submission to the tribunal.

\footnotetext{
${ }^{150}$ Orna Rabinovich-Einy and Ethan Katsh, 'Digital Justice: Reshaping Boundaries in an Online Dispute Resolution Environment' (2014) 1(1) International Journal of Online Dispute Resolution 5, 27-8.

${ }^{151}$ The Resolve to Resolve (n 59) 72.
} 
In cases involving parties with limited English proficiency, machine translation might be used to help explain the forms and legal concepts therein. However, issues with accuracy of translation may arise. For this reason, sole reliance must not be placed on machine or automated translation. There must also be sufficient triage to assess whether any solution as presented by the platform is indeed the appropriate solution or whether further referral or investigation is needed. In such cases, the platform should be able to provide information about its limitations as well as about the issues on which parties will want additional help and referrals.

Furthermore, Condlin contends that a public ODR system must be able to

enforce the expressive dimension of law, serve the therapeutic ends of disputing, and accommodate the attitudes, feelings, and beliefs of the participants, as much as protect their money, time, and convenience. ${ }^{152}$

Whether an ODR platform can function in such a way will depend largely on the design of the system. The platform must allow parties to define and explain and defend their claims fully in accordance with a set of substantive, evidentiary and procedural rules that all parties in the process are aware of and accept as legitimate.

In addition, legal validity is a value which must be intrinsic to a public ODR platform. The activities of tribunals, courts and judges must conform to legally valid procedures and comply with valid laws. The adherence to such procedures and laws is the foundation of the legal system and the basis for public legitimacy. As a result, any digitisation of procedures which will bind the users of the platform must be done in accordance with accepted norms and supported by legislative instruments. For example, e-filing systems should not allow access to users who falsify their identity or documents. Users who perceive digital procedures to be different from formal procedures may question the legitimacy of such procedures. This can, in turn, affect the adoption of the online platform and erode the recognition of the legality of forensic data submitted and exchanged through the platform.

It is argued that the more automated the ODR system is, the higher the level of trust required from its users and the more transparent it should be. The extent of the use of automated software (if any) in the final platform to be adopted by VCAT is presently unclear. Regardless of this, there is a need for further research into the limits of algorithmic 'expertise' and the implicit

\footnotetext{
152 Robert J Condlin, 'Online Dispute Resolution: Stinky, Repugnant, or Drab' (2017) 18(3) Cardozo Journal of Conflict Resolution 717, 734 (citation omitted).
} 
'jurisprudential premise of ODR - that outcomes dictated by algorithms based on Big Data and crowdsourced data will produce just results .... ${ }^{153}$ According to Condlin, such a premise is not anchored 'in any well-known political or jurisprudential theory of procedural fairness and substantive justice'. ${ }^{154} \mathrm{He}$ argues that the premise is inherently unsound as '[ $t$ ] he algorithms in question are proprietary in nature and thus known only to their owners and creators'. ${ }^{155}$ In his opinion, a system of public dispute resolution should be based on substantive standards and procedural rules that are transparent. He argues that

[c]rowdsourced data can provide helpful alternatives to present proposals, and Big Data can provide helpful benchmarks against which to test tentative resolutions, but neither is a source of legal or political legitimacy in its own right, or necessarily a reflection of a society's principled commitments embodied in its laws. ${ }^{156}$

Proponents of ODR, such as Rabinovich-Einy and Katsh agree that technology is not neutral. It is 'designed by people who have their own set of biases, assumptions and values, and their impact needs to be uncovered and analysed' ${ }^{157}$ However, they go on to contend that some types of software are capable of uncovering the 'biases in the design and guide parties through a thoughtful process, uncovering their interests and questioning their biases and assumptions'. ${ }^{158}$ Where biases cannot be prevented or uncovered in an individual case, available data and documentation may present problematic outcome patterns and this can in turn help expose potential biases in the system design. ${ }^{159}$

Condlin has also claimed that the principal forces behind the expansion of ODR into the spheres of public and civil disputes are the same "forces behind many popular movements in the present day - money and convenience' ${ }^{160}$ In redefining the traditional dispute resolution processes, software will be designed to support, and in some cases, replace humans.

Attracted by the possibility of faster, cheaper and more convenient dispute resolution, companies, states of the union, and countries around the world

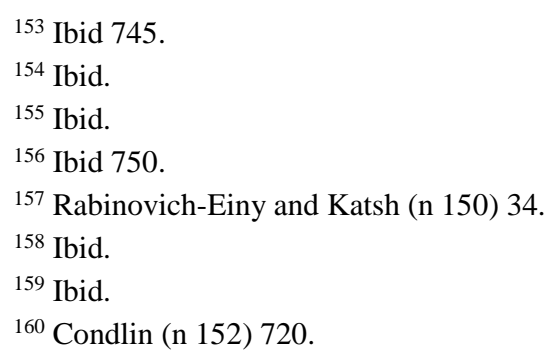


now have begun to create ODR programs on a scale that makes the process, along with outsourcing, AI-based practice management software, and nontraditional legal service providers, one of the principal forces redefining the traditional practice of law. ${ }^{161}$

He is highly critical of the results of software controlled ODR systems and questions whether 'the cheap and efficient processing of disputes is a capitulation to the conditions of modern society more than a superior system for administering justice'. ${ }^{162}$ For example, most ODR systems will require parties to explain their claims in fixed or pre-defined parts. This means that the systems may not capture all the dimensions of the claims and parties may not be able to recover the entire claim's worth. Condlin adds that ODR systems may also restrict parties' ability to argue the substantive merits of their claims. This is especially the case for highly automated ODR systems which utilise predictive negotiation algorithms as a major part of the resolution process. '[U]ncoupling disputes from their substantive merits can undermine the fairness of individual outcomes and, if widespread, threaten the legitimacy of dispute resolution systems themselves. '163 The question then becomes: how much reliance on algorithms is too much? According to Condlin:

When not based on normative standards, dispute resolution is just another form of bureaucratic processing, the resolution of disagreements according to a set of tacit, often biased, intra-organizational, administrative norms (e.g., seller is always correct), that are defined by repeat players who 'capture' the system and use it for their private ends. ${ }^{164}$

Related to legal validity is the requirement of transparency and accountability. The platform and its systems must also be accountable in their own right. On one level, the technology can provide useful data to drive continuous improvement of the tribunal's processes - such information as the average time to process a case from filing to videoconferencing or the average time required to access stored information. The technology can also monitor the quality of processes and outcomes and detect biases and problems in the algorithms.

On another level, potential lack of transparency and biases associated with algorithms can give rise to a lack of trust in the platform. This issue will need

\footnotetext{
${ }^{161}$ Ibid 721.

${ }^{162}$ Ibid. The distinction was made between software-controlled systems as opposed to systems controlled by humans. Condlin limited his comments to systems which are controlled either exclusively or principally by software.

${ }^{163}$ Ibid 722.

${ }^{164}$ Ibid (citation omitted).
} 
to be addressed if the platform relies on such algorithms, and particularly if they take the form of learning algorithms. ' $[\mathrm{B}] \mathrm{y}$ its nature, deep learning [AI] is a particularly dark black box. ${ }^{165}$ There must be transparency in terms of how the algorithms work, the identities and affiliations of the ODR providers and the management of the systems. Without this, there can be no accountability for the systems.

Ultimately, this article argues that, in cases involving traditional small-claims disputes in courts or tribunals such as VCAT, the use of AI in an ODR platform should be limited to the preliminary stages of dispute resolution where parties can be advised of the potential outcomes of their disputes based on previous patterns of disputes. Such benefits from advancements in technology should be extended to the court system which has also been increasingly adopting technology into case management and other court services.

\section{CONCLUSION}

In many jurisdictions, a key driver of ODR is the need for inexpensive access to justice to be provided to consumers with small claims. The characteristics of many consumer disputes make them ill-suited for court proceedings. It is argued that an effective consumer redress system must provide consumers with access to a low cost and high-convenience forum to help them resolve disputes. The outcome of the recent VCAT pilot, along with the success of the implementation of end-to-end ODR in tribunals such as the Civil Resolution Tribunal in British Columbia, have helped to demonstrate the potential use of ODR to improve access to justice. There are many aspects of the dispute resolution processes which can be implemented online.

This article contends that, as ODR continues to permeate the public sector, further debate on the preservation of the values of civil justice and consumer protection must take place. It is important that a public ODR platform is transparent and capable of improving judicial and court or tribunal accountability. Appropriate dispute system design principles must be used to ensure that an ODR platform fulfils its intended objectives, provides a highquality alternative to the courts and maintains its legitimacy amongst its users.

Finally, the questions of how much technology should be used in dispute resolution, in what circumstances, and at what cost, must also continue to be explored. Technological innovation should not result in the erosion of

\footnotetext{
${ }^{165}$ Will Knight, 'The Dark Secret at the Heart of AI' MIT Technology Review (11 April 2017) $<$ https://www.technologyreview.com/s/604087/the-dark-secret-at-the-heart-of-ai/>.
} 
fundamental values of civil justice including accessibility, transparency, legal validity and accountability. 